\title{
Evaluation of fungicides and sterilants for potential application in the management of Fusarium wilt of banana
}

\author{
B. Nel ${ }^{\mathrm{a}}$, C. Steinberg ${ }^{\mathrm{b}}$, N. Labuschagne ${ }^{\mathrm{a}}$ and A. Viljoen ${ }^{\mathrm{a}}$ \\ ${ }^{a}$ Department of Microbiology and Plant Pathology, Forestry and Agricultural \\ Biotechnology Institute (FABI), University of Pretoria, Pretoria 0002, South Africa \\ ${ }^{b}$ INRA-CMSE-Université de Bourgogne, 17 rue Sully-BP 86510, F. 21065 DIJON \\ CEDEX, Dijon, France
}

\section{Abstract}

Fusarium wilt is considered one of the most important diseases of bananas. The disease can only be managed by using resistant cultivars and by preventing its introduction into new fields. The objectives of this study were to evaluate newly available fungicides, in vitro and in vivo, for their efficacy against the responsible pathogen Fusarium oxysporum f.sp. cubense, and to evaluate surface sterilants that could be used for sterilization purposes. Of the fungicides, prochloraz and propiconazole significantly inhibited mycelial growth at concentrations of 1 and $5 \mu \mathrm{g} \mathrm{ml}^{-1}$, respectively. Benomyl and the demethylation-inhibiting fungicides significantly reduced the disease severity of FoC when applied as a root dip treatment, showing disease reduction up to $80.6 \%$. The results also demonstrated that certain quaternary ammonium compounds are effective as sterilants against $F O C$ and should replace the ineffective sterilants that are currently being used. Further field evaluations of the fungicides are required. 


\section{Article Outline}

1. Introduction

2. Materials and methods

2.1. Isolates used and inoculum preparation

2.2. Selection of fungicides and surface sterilants

2.3. Evaluation of fungicides

2.3.1. In vitro evaluation

2.3.2. In vivo evaluation

2.4. Evaluation of surface sterilants

2.5. Statistical analysis

3. Results

3.1. Evaluation of fungicides

3.1.1. In vitro evaluation

3.1.2. In vivo evaluation

3.2. Evaluation of surface sterilants

4. Discussion

Acknowledgements

References

\section{Introduction}

Fusarium wilt of banana (Panama disease) is caused by the soil-borne fungus Fusarium oxysporum f. sp. cubense (E.F. Smith) Snyder and Hansen (Foc) (Stover, 1962). The fungus infects the roots of banana plants, colonising the vascular system of the rhizome and pseudostem, and inducing characteristic wilting symptoms before the plant eventually dies (Wardlaw, 1961; Stover, 1962). Evidence suggests that Foc originated in Southeast Asia (Ploetz and Pegg, 1997) and from there was disseminated rapidly throughout the world with infected rhizomes (Stover, 1962). During the first half of the 20th century, Fusarium wilt caused major destruction in the Central American region, and since Panama was one of the most severely affected countries, the name Panama disease was adopted (Jeger et al., 1996). Due to the destruction Foc race 1 caused in Central 
America, the international export trade was forced to convert from the susceptible Gros Michel to the resistant Cavendish cultivars (Ploetz et al., 2003). Unfortunately, Cavendish cultivars are highly susceptible to race 4 of Foc (Ploetz and Pegg, 2000). Fusarium wilt of banana is controlled effectively by applying disease-preventive practices such as planting in fields not infested with Foc using disease-free propagation material. Once infested with the pathogen, the only way of continuing banana production is by means of planting cultivars with resistance to the disease (Deacon, 1984; Ploetz and Pegg, 2000; Viljoen, 2002; Ploetz et al., 2003). Cultivars with resistance to Foc have been identified, but these cultivars are not always acceptable to local markets (Viljoen, 2002). While research programmes around the world now aim at producing Cavendish bananas with resistance against pests and diseases, efforts to develop an integrated management programme for Fusarium wilt should not be neglected. Such a programme could combine disease tolerance with strategies such as chemical, biological and cultural control.

Before Gros Michel was replaced with Cavendish bananas in Central America in the 1960s, several studies investigated the potential application of chemical and cultural control strategies in Fusarium wilt management (Stover, 1962). Various laboratory and greenhouse evaluations of fungicides were performed, and some of these compounds were found to effectively inhibit Foc growth during in vitro studies and in the greenhouse (Meredith, 1943; Corden and Young, 1959 and Corden and Young, 1960; Stover, 1962). However, the fungicides that performed best in these studies were unable to control Fusarium wilt effectively in the field (Meredith, 1943; Stover, 1962). After 1960, few reports can be found on the use of fungicides for the control of Foc. In South Africa, Deacon (1984) recommended that every banana sucker should be washed free of soil and inspected for the presence of the disease, followed by a dip treatment with a fungicide mix before planting, in order to limit the spread of the disease. In India, stem injections with carbendazim decreased the disease incidence of cultivar Rastali (i.e. Silk), but it proved to be ineffective in South Africa (Lakshmanan et al., 1987; Herbert and Marx, 1990). Even though it is clear that chemical control of Fusarium wilt of banana has received little attention in the past 40 years, fungicides remain an important part of disease control strategies. The significant discovery of new fungicides has often led to a 
series of follow-up products, which should be considered when designing an integrated disease management programme (Gullino et al., 2000).

Fusarium wilt of banana has been disseminated from one country or growing region to another by means of infected rhizomes or suckers and adhering soil. These rhizomes and suckers often did not exhibit symptoms (Moore et al., 1995). Within production areas or between fields, the pathogen is spread to non-infested areas in contaminated irrigation water, and with farm equipment, shoes and vehicles (Ploetz, 1994). The use of effective disinfectants or surface sterilants is, therefore, essential in preventing the spread of Foc. Disinfecting Foc-infested soil in small areas by drenching with copper sulfate, carbolineum and formaldehyde proved to be unsuccessful and expensive (Brandes, 1919). In Jamaica, Rishbeth and Naylor (1957) found carbon disulphide and formalin ineffective and unreliable when evaluated as soil disinfectants. Even soil fumigation with methyl bromide proved to be effective only as a short-term control measure in South Africa, due to the successful re-invasion of the pathogen after a period of approximately 2 years (Herbert and Marx, 1990). The application of surface disinfectants for the cleaning of equipment, shoes and machinery is more effective and appropriate. In Australia, a commercial product 'Farmcleanse' was found to be the most effective disinfectant for eradication of Foc spores when compared to other fungicides and quaternary ammonium compounds (Moore et al., 1999). 'Farmcleanse' is a detergent-based degreaser with a quaternary ammonium additive that has replaced chlorine bleach, methylated spirits and copper oxychloride solutions as disinfectant of vehicles, farm equipment and in footbaths, since it is non-corrosive and more environmentally friendly (Moore et al., 1999). In South Africa, copper oxychloride was almost exclusively used for the disinfection of vehicles, farm equipment and shoes prior to this study (Viljoen, personal communication).

The aim of this study was, firstly, to screen a range of fungicides, including new chemical formulations, for their ability to inhibit mycelial growth of Foc in vitro. Secondly, the aim was to determine the efficacy of some of these fungicides against banana wilt in the greenhouse, and lastly, to evaluate the efficacy of various surface sterilants in eradicating Foc contamination. 


\section{Materials and methods}

\subsection{Isolates used and inoculum preparation}

All isolates of Foc used in this study represent subtropical race 4 (VCG 0120), and were isolated from diseased banana plants in South Africa. Their virulence to banana plantlets and their cultural characteristics were established earlier by Groenewald et al. (2006). For the in vitro evaluation of fungicides, a slow (CAV 031) and a fast growing (CAV 086) isolate were selected. For the in vivo studies, two highly virulent isolates (CAV 045 and CAV 092) were selected. These isolates were all grown for $7 \mathrm{~d}$ at $25^{\circ} \mathrm{C}$ on half-strength potato dextrose agar (PDA) (19 g of Difco PDA powder, $19 \mathrm{~g}$ of Biolab agar, $1000 \mathrm{ml}$ $\mathrm{H}_{2} \mathrm{O}$ ) under cool-white and near-ultraviolet fluorescent lights before being used for fungicide evaluation. Mycelial plugs $(0.5 \mathrm{~cm}$ in diameter) from the margins of these cultures were aseptically transferred to the centres of fungicide-amended PDA for the in vitro studies, and inoculated on autoclaved millet seeds in 500-ml Erlenmeyer flasks for the in vivo studies. Inoculated flasks were incubated at $25^{\circ} \mathrm{C}$ for 2 weeks during which the flasks were shaken twice weekly to ensure equal distribution of the inoculum. Infested millet seeds were then added to steam-pasteurised soil at a rate of $15 \mathrm{ml}$ seeds per $500 \mathrm{ml}$ soil and thoroughly mixed to obtain a final concentration of $3 \%(\mathrm{v}: \mathrm{v})$ inoculum in the soil.

For evaluation of sterilants, a pathogenic isolate of Foc (CAV 027) was grown for $7 \mathrm{~d}$ on half-strength PDA at $25^{\circ} \mathrm{C}$ under cool-white and near-ultraviolet fluorescent lights. To prepare a conidial spore suspension, mycelia were transferred into 250-ml Erlenmeyer flasks containing Armstrong Fusarium medium (Booth, 1977). The flasks were placed on a rotary shaker operating at $170 \mathrm{rpm}$ at $25^{\circ} \mathrm{C}$ for $5 \mathrm{~d}$, after which the conidial suspension was passed through cheesecloth to separate the mycelium from the spores. The spore concentration in the remaining liquid medium was determined using a hemacytometer, and diluted with sterile distilled water to a final concentrations of $10^{5}$ spores $\mathrm{ml}^{-1}$.

\subsection{Selection of fungicides and surface sterilants}

Nine fungicides, representative of seven chemical groups, were selected for in vitro evaluation against FOC (Table 1). These fungicides included several new commercial products that had not previously been tested for activity against Foc. All the fungicides 
were tested for efficacy against both Foc isolates mentioned earlier, except for phosetyl$\mathrm{Al}$ that was only evaluated against CAV 086. Five fungicides evaluated in vivo were selected on the basis of their performance in the in vitro evaluation. Before fungicide trials were conducted, the chemicals were tested for phytotoxicity on banana plants and the optimal concentration at which chemicals should be applied to the plantlets was determined. Chemicals were tested for phytotoxicity at concentrations of 5, 10, 25 and $50 \mu \mathrm{g} \mathrm{ml}^{-1}$ active ingredient (a.i.). Nine commercially available surface sterilants were also selected for evaluation against Foc at four different spore concentrations (Table 2). Table 1.

Fungicides evaluated in vitro and in vivo against Fusarium oxysporum f.sp. cubense

\begin{tabular}{|l|l|l|l|}
\hline Chemical group & Active ingredient & \multicolumn{2}{|l|}{ Formulation } \\
\hline & & Type $^{\mathbf{a}}$ & \% Active ingredient \\
\hline Benzimidazole & Benomyl & WP & $500 \mu \mathrm{g} \mathrm{g}^{-1}$ \\
\hline Copper compounds & Copper oxychloride & WP & $850 \mu \mathrm{g} \mathrm{g}^{-1}$ \\
\hline DMI-imidazole & Prochloraz & EC & $450 \mu \mathrm{g} \mathrm{ml}^{-1}$ \\
\hline DMI-triazole & Cyproconazole/propiconazole & EC & $330 \mu \mathrm{g} \mathrm{ml}^{-1}$ \\
\hline DMI-triazole & Propiconazole & EC & $250 \mu \mathrm{g} \mathrm{ml}^{-1}$ \\
\hline Phosphorous acid & Phosetyl-Al & Soln & $200 \mu \mathrm{g} \mathrm{ml}^{-1}$ \\
\hline Phthlalimide & Captab & WP & $500 \mu \mathrm{g} \mathrm{g}^{-1}$ \\
\hline Strobilurins & Azoxystrobin & Gran & $500 \mu \mathrm{g} \mathrm{g}^{-1}$ \\
\hline Strobilurins & Kresoxim-methyl & EC & $500 \mu \mathrm{g} \mathrm{g}^{-1}$ \\
\hline
\end{tabular}

${ }^{\mathrm{a}} \mathrm{WP}$, wettable powder; EC, emulsifiable concentrate; Gran, granule; Soln, solution. 
Table 2.

Surface sterilants evaluated in vitro against Fusarium oxysporum f.sp. cubense

\begin{tabular}{|l|l|}
\hline Trade name & Active ingredient \\
\hline Chloride & Ca-hypochloride \\
\hline Clean Green & Non-ammonium compound \\
\hline Cupravit & Copper oxychloride \\
\hline Desogerm & Biquanidine and quaternary ammonium compound \\
\hline Farmcleanse & Quaternary ammonium compound \\
\hline Jik & Sodium hypochloride \\
\hline Prazin agri & $\begin{array}{l}\text { Polymeric biquanidine hydrochloride and quaternary ammonium } \\
\text { compound }\end{array}$ \\
\hline Omega & Prochloraz \\
\hline Sporekill & Poly dimethyl ammonium chloride \\
\hline
\end{tabular}

\subsection{Evaluation of fungicides}

\subsubsection{In vitro evaluation}

Fungicides were suspended in sterile distilled water and added to autoclaved PDA to achieve final concentrations of $1,5,10,50,100 \mu \mathrm{g} \mathrm{ml}^{-1}$ (a.i.). The fungicide-amended PDA was dispensed aseptically into 9-cm-diameter plastic Petri dishes. Mycelial plugs of single-spore isolates of FOC were then transferred to the centres of the fungicide-amended media. The dishes were incubated for $7 \mathrm{~d}$ at $25{ }^{\circ} \mathrm{C}$ under cool-white and near-ultraviolet fluorescent lights, after which colony diameter was measured (two perpendicular measurements per colony). The mycelial growth on the fungicide-amended PDA was compared with the growth of the pathogen on unamended PDA plates that served as controls. Each treatment was replicated five times. The in vitro study was conducted twice.

\subsubsection{In vivo evaluation}

Pathogen-free tissue culture banana plantlets (of the Cavendish cultivar Chinese Cavendish) were obtained from Du Roi Laboratories in Letsitele, South Africa. The 5-cm plantlets were removed from the seedling trays and their roots washed in tap water to 
remove excess sterile soil. The plants were then placed in 250-ml plastic cups filled with a nutrient solution consisting of $0.45 \mathrm{~g}^{\text {Agrasol }^{\circledR}}{ }^{\circledR} \mathrm{O}$ 3:2:8 (Fleuron, P.O. Box 31245, Braamfontein, 2017), $0.3 \mathrm{~g}$ calcium nitrate monohydrate and $0.15 \mathrm{~g} \mathrm{Micromix}^{\circledR}$ (Fleuron) $1^{-1}$ tap water, with a $\mathrm{pH}$ of 7.0. The plastic cups were covered with lids provided with a hole in the middle. The plantlets were suspended through the holes while their stems were supported with strips of foam rubber. The nutrient solution was replaced weekly. The plants were grown for 4 weeks to allow for ample root development, before they were used for the in vivo evaluations of fungicides.

Plants with roots of more or less uniform length $(15.0 \pm 0.5 \mathrm{~cm})$ were selected for greenhouse evaluation of fungicides against Fusarium wilt. All roots were slightly bruised by manually squeezing the rootball by hand to facilitate infection by the pathogen. Three application methods were tested for each fungicide, namely root dipping at planting, soil drenching immediately after planting, and soil drenching 1 week after planting. For the root dipping, roots of the banana plantlets were submerged for $10 \mathrm{~min}$ in a $25 \mu \mathrm{g} \mathrm{ml}^{-1}$ (a.i.) concentration of the five selected fungicides, respectively, and replanted in 12.5 -cm-diameter pots containing steam-pasteurised soil infested with a $3 \%$ millet seed inoculum of Foc. Soil drench applications were made after plants had been replanted by applying $100 \mathrm{ml}$ of a $25 \mu \mathrm{g} \mathrm{ml}{ }^{-}$(a.i.) concentration of each fungicide. Plants receiving soil drench treatments 1 week after planting were treated at the same dosage rate. Control plants were treated with $100 \mathrm{ml}$ distilled water and planted in soil infested and uninfested with Foc, respectively. The plants were transferred to phytotrons with a photoperiod of $12 \mathrm{~h}$ and at a day/night temperature regime of $28 / 20^{\circ} \mathrm{C}$ for 7 weeks. Six replicate plants were used for each treatment, and the trial was repeated. Disease development was estimated by cutting the pseudostem open with a scalpel and by assigning a disease severity rating to each plant according to Inibab's Technical Guidelines number 6 (Carlier et al., 2002).

\subsection{Evaluation of surface sterilants}

In vitro tests were performed to evaluate various compounds for efficacy in the sterilization of contaminated equipment, shoes, and vehicles. The test compounds were prepared in sterile distilled water at concentrations of $0.01,0.1,1$ and 10 times the 
recommended dosages. Foc microconidia were added to these suspensions to obtain final concentrations of $10^{5}$ spores $\mathrm{ml}^{-1}$. After an exposure time of $5 \mathrm{~min}$, a dilution series of $10^{4}, 10^{3}, 10^{2}$ and $10^{1}$ was prepared and plated onto PDA plates and incubated at $25^{\circ} \mathrm{C}$ under cool-white and near-ultraviolet fluorescent lights. Sterile distilled water containing FOC spores were used as controls. The developing Foc colonies were counted after 4d. In addition, three sterilants that showed the greatest effect on Foc conidia were tested at different exposure time intervals of $30 \mathrm{~s}, 5,15$ and $30 \mathrm{~min}$. The entire experiment was repeated with five replicates per treatment. After plating of a dilution series on PDA, the number of developing Foc colonies was recorded.

\subsection{Statistical analysis}

Data from repetitive in vitro fungicide experiments were pooled and subjected to analysis of variance (ANOVA). Mean differences were separated according to Duncan's Multiple Range $(P \leqslant 0.05)$. Data obtained for the greenhouse trials were discrete and required a non-parametric analysis. Data were analysed based on Wilcoxon scores (Sokal and Rohlf, 1981). Differences between treatments were significant at $P \leqslant 0.05$ (SAS Institute Inc., SAS/STAT Users Guide, Version 8, Cary, NC: SAS Institute Inc., 1999). Data from the surface sterilant evaluations were pooled and analysed based on the General Linear Model Procedure (GLM) as described in SAS (SAS Institute Inc., SAS/STAT Users Guide, Version 8, Cary, NC, 1999). Differences between treatments were significant at $P \leqslant 0.05$.

\section{Results}

\subsection{Evaluation of fungicides}

\subsubsection{In vitro evaluation}

All fungicides, except benomyl and captab at a concentration of $1 \mu \mathrm{g} \mathrm{ml}^{-}$(a.i.), significantly reduced the mycelial growth of Foc isolate CAV 086 in culture (Fig. 1A). The demethylation-inhibiting (DMI) fungicides (prochloraz, propiconazole and the combination of cyproconazole and propiconazole), however, were the most effective. Of the nine fungicides evaluated, prochloraz was the only one to inhibited mycelial growth of Foc completely at all concentrations tested. The two DMI-triazole fungicides, the 
combination of cyproconazole and propiconazole, as well as propiconazole, at a concentration of $5 \mu \mathrm{g} \mathrm{ml}^{-1}$ (a.i.), also completely inhibited growth of the pathogen in vitro (data not presented). Benomyl was also effective but to a lesser degree. Conversely, media amended with copper oxychloride, captab, azoxystrobin and phosetyl-Al (aluminium tris-[o-ethyl phosphonate]) showed poor inhibition of Foc growth, even at $100 \mu \mathrm{g} \mathrm{ml} l^{-1}$ (a.i). Although phosetyl-Al did not show total inhibition of growth, it reduced the density of the mycelia visibly. 

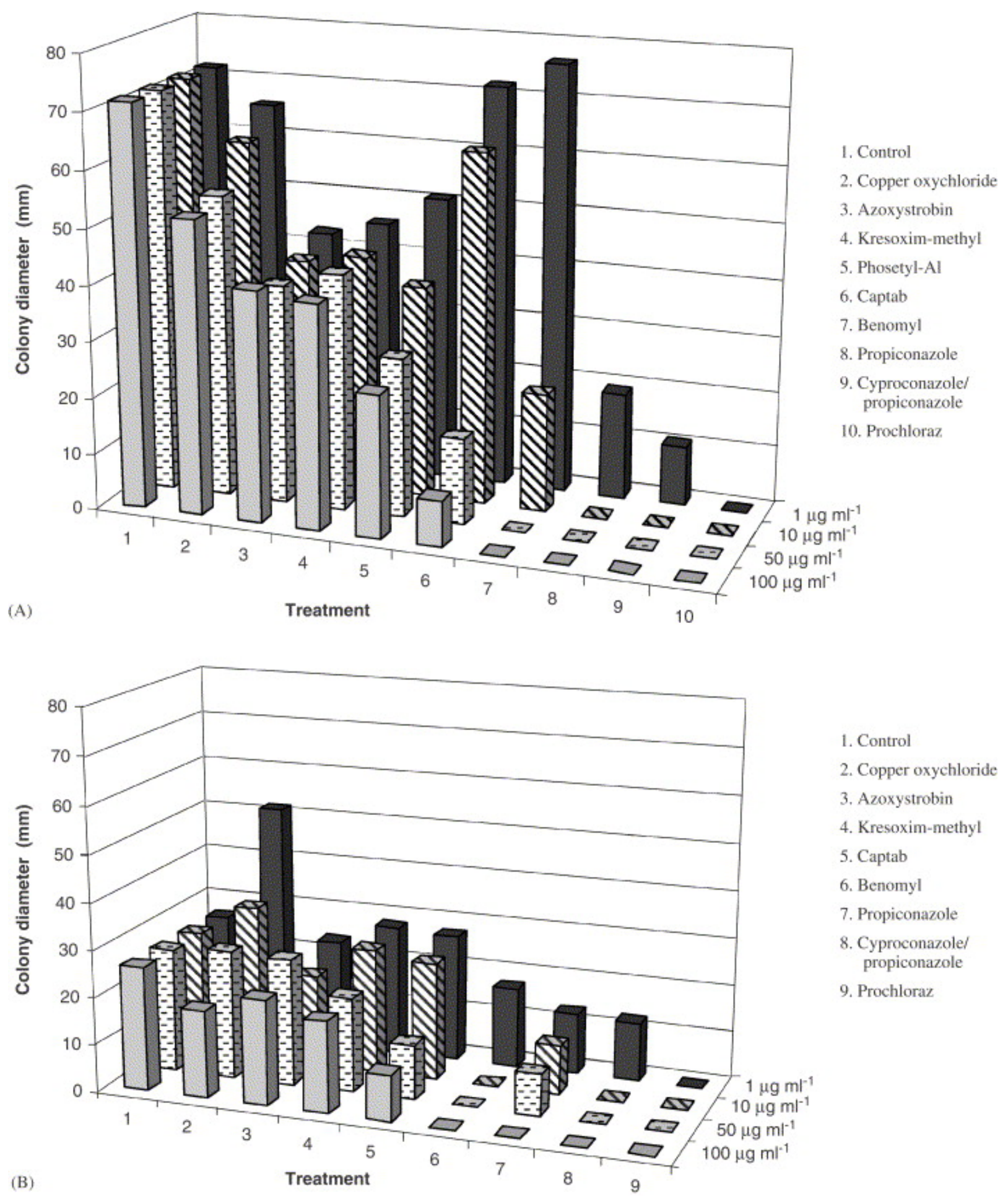

Fig. 1. Effect of fungicides on the mycelial growth of Fusarium oxysporum f.sp. cubense isolates CAV 086 (A) and CAV 031 (B) on potato dextrose agar. Mean differences were separated according to Duncan's Multiple Range test (P $\leqslant \mathbf{0 . 0 5})$. (A) LSD=2.952; (B) $\mathrm{LSD}=2.195$. 
Results obtained with Foc isolate CAV 031 and with the fast growing isolate CAV 086 were similar, although copper oxychloride, azoxystrobin and kresoxim-methyl were less effective against CAV 031 (Fig. 1). Prochloraz was again the most effective fungicide, showing total inhibition of fungal growth at all the concentration tested (Fig. 1B). Prochloraz was followed by cyproconazole/propiconazole and benomyl, which restricted growth at concentrations of $10 \mu \mathrm{g} \mathrm{ml}^{-1}$ (a.i.) and higher. Propiconazole completely inhibited fungal growth at concentrations of $100 \mu \mathrm{g} \mathrm{ml}^{-1}$ (a.i.). The fungicides captab, kresoxim-methyl, azoxystrobin and copper oxychloride were less effective.

\subsubsection{In vivo evaluation}

Banana plants treated with all the chemicals at concentrations of $50 \mu \mathrm{g} \mathrm{ml}^{-1}$ (a.i.) developed severe symptoms of phytotoxicity (data not presented). When treated at concentrations of 5, 10 and $25 \mu \mathrm{g} \mathrm{ml}^{-1}$ (a.i.), none of the plants developed signs of phytotoxicity. The fungicide benomyl and the DMI fungicides prochloraz, propiconazole and cyproconazole/propicaonazole significantly reduced the incidence of Foc with the root dip and soil drench treatments 1 week after planting (Fig. 2).

Cyproconazole/propicaonazole, applied as root dip treatment, was the most effective in reducing the disease severity, resulting in a disease reduction of $80.6 \%$ (Table 3 ). Prochloraz and propiconazole were also highly effective as root dip treatments, with disease reductions of $77.8 \%$ and $75.0 \%$, respectively. Benomyl was found the most effective applied as a soil drench treatment 1 week after planting and resulted in disease reduction of $72.2 \%$ (Table 3). Phosetyl-Al, applied to the banana plantlets either as root dip or soil drench treatments, resulted in no significant reduction in the disease severity. The external symptoms on the plants were not as informative as the internal symptoms, although slight differences could be observed. No internal discoloration was observed in the uninfested control plants, while the infested control plants showed a high level of disease severity based on internal discoloration. 


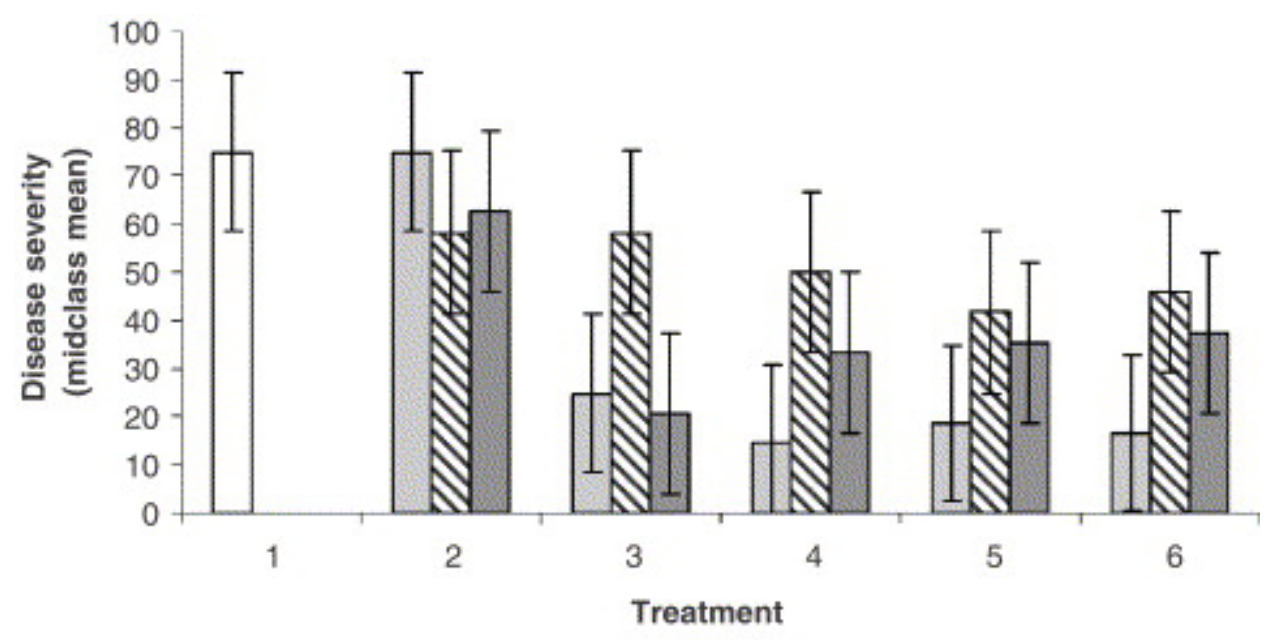

Root dip $\mathbf{\Delta}$ Soil drench $\mathbf{\square}$ Soil drench 1 week later

Fig. 2. Effect of different fungicides in controlling Fusarium wilt development caused by Fusarium oxysporum f.sp. cubense in the banana cultivar Chinese Cavendish in the greenhouse. Treatments were as follow: (1) control, (2) phosetyl-Al, (3) benomyl, (4) cyproconazole/propiconazole, (5) propiconazole and (6) prochloraz. Midclass mean was calculated taking into account the disease severity in all six plants per treatment. Range bars represent $95 \%$ confidence intervals.

Table 3.

Effect of fungicide treatments on severity of Fusarium wilt caused by Fusarium oxysporum f.sp. cubense (Foc) on the banana cultivar Chinese Cavendish in the greenhouse

\begin{tabular}{|c|c|c|c|}
\hline Treatment & $\begin{array}{l}\text { Disease severity } \\
\text { (\%) }\end{array}$ & $\begin{array}{l}\text { Disease reduction } \\
(\%)\end{array}$ & $\begin{array}{l}P \text { - } \\
\text { value }^{\text {b }}\end{array}$ \\
\hline Uninfested control $^{\mathbf{c}}$ & 0.0 & & \\
\hline Infested control control $^{\mathbf{d}}$ & 75.0 & & \\
\hline \multicolumn{4}{|l|}{ Phosetyl-Al } \\
\hline Root dip ${ }^{\mathbf{e}}$ & 75.0 & - & 1.0000 \\
\hline Soil drench after planting $\mathbf{f}$ & 58.3 & 22.2 & 1.0000 \\
\hline $\begin{array}{l}\text { Soil drench } 1 \text { week after } \\
\text { planting }\end{array}$ & 62.5 & 16.7 & 1.0000 \\
\hline
\end{tabular}




\begin{tabular}{|c|c|c|c|}
\hline Treatment & $\begin{array}{l}\text { Disease severity } \\
(\%)\end{array}$ & $\begin{array}{l}\text { Disease reduction } \\
(\%)\end{array}$ & $\begin{array}{l}P \text { - } \\
\text { value }^{b}\end{array}$ \\
\hline \multicolumn{4}{|l|}{ Benomyl } \\
\hline Root dip & 25.0 & 66.7 & 0.0055 \\
\hline Soil drench after planting & 58.3 & 22.2 & 1.0000 \\
\hline $\begin{array}{l}\text { Soil drench } 1 \text { week after } \\
\text { planting }\end{array}$ & 20.8 & 72.2 & 0.0014 \\
\hline \multicolumn{4}{|c|}{ Cyproconazole/propiconazole } \\
\hline Root dip & 14.6 & 80.6 & 0.0002 \\
\hline Soil drench after planting & 50.0 & 33.3 & 1.0000 \\
\hline $\begin{array}{l}\text { Soil drench } 1 \text { week after } \\
\text { planting }\end{array}$ & 33.3 & 55.6 & 0.0674 \\
\hline \multicolumn{4}{|l|}{ Propiconazole } \\
\hline Root dip & 18.8 & 75.0 & 0.0007 \\
\hline Soil drench after planting & 41.7 & 44.4 & 0.6213 \\
\hline $\begin{array}{l}\text { Soil drench } 1 \text { week after } \\
\text { planting }\end{array}$ & 35.4 & 52.8 & 0.1209 \\
\hline \multicolumn{4}{|l|}{ Prochloraz } \\
\hline Root dip & 16.7 & 77.8 & 0.0004 \\
\hline Soil drench after planting & 45.8 & 38.9 & 1.0000 \\
\hline $\begin{array}{l}\text { Soil drench } 1 \text { week after } \\
\text { planting }\end{array}$ & 37.5 & 50.0 & 0.2129 \\
\hline
\end{tabular}

${ }^{a}$ Mean of six plants per treatment. Disease severity assessed by visually rating individual plants according to Inibab's Technical Guidelines number 6 (Carlier et al., 2002).

${ }^{\mathrm{b}}$ Comparison of control with treatment by means of $t$-test (LSD).

${ }^{\mathrm{c}}$ Plants treated with distilled water and planted in uninfested soil.

${ }^{\mathrm{d}}$ Plants treated with distilled water and planted in soil infested with Foc (CAV 045 and CAV 092) pathogenic isolates.

${ }^{\mathrm{e}}$ Roots of plants were dipped in a $25 \mu \mathrm{g} \mathrm{ml}{ }^{-1}$ (a.i.) suspension of each fungicide for $10 \mathrm{~min}$. 
${ }^{\mathrm{f}}$ Plants were drenched with $100 \mathrm{ml}$ of a $25 \mu \mathrm{g} \mathrm{ml} \mathrm{l}^{-1}$ (a.i.) suspension of each fungicide immediately after planting.

${ }^{\mathrm{g}}$ Plants were drenched with $100 \mathrm{ml}$ of a $25 \mu \mathrm{g} \mathrm{ml}{ }^{-1}$ (a.i.) suspension of each fungicide 1 week after planting.

\subsection{Evaluation of surface sterilants}

The most conclusive results were obtained when the sterilants were applied to a spore concentration of $10^{2}$ spores $\mathrm{ml}^{-1}$. Therefore, data from only this concentration is presented in Fig. 3. All the sterilants showed a reduction in the number of Foc colonies that developed when applied at a concentration of 10 times the recommended dosage (Fig. 3), with an exposure time of $5 \mathrm{~min}$. A dose-dependent response could be observed, with the efficacy of the sterilants increasing when higher concentrations of the sterilants were used. Of all the sterilants tested, Sporekill, Jik and Prazin proved to be the most effective at all concentrations, killing all Foc conidia, with the exception of a concentration of 0.01 of the recommended dosage. Sporekill, Prazin and Jik were effective at exposure times of 5,15 and $30 \mathrm{~min}$ (data not presented). Sporekill was the only sterilant that showed no Foc survival after an exposure time of $30 \mathrm{~s}$ (data not presented).

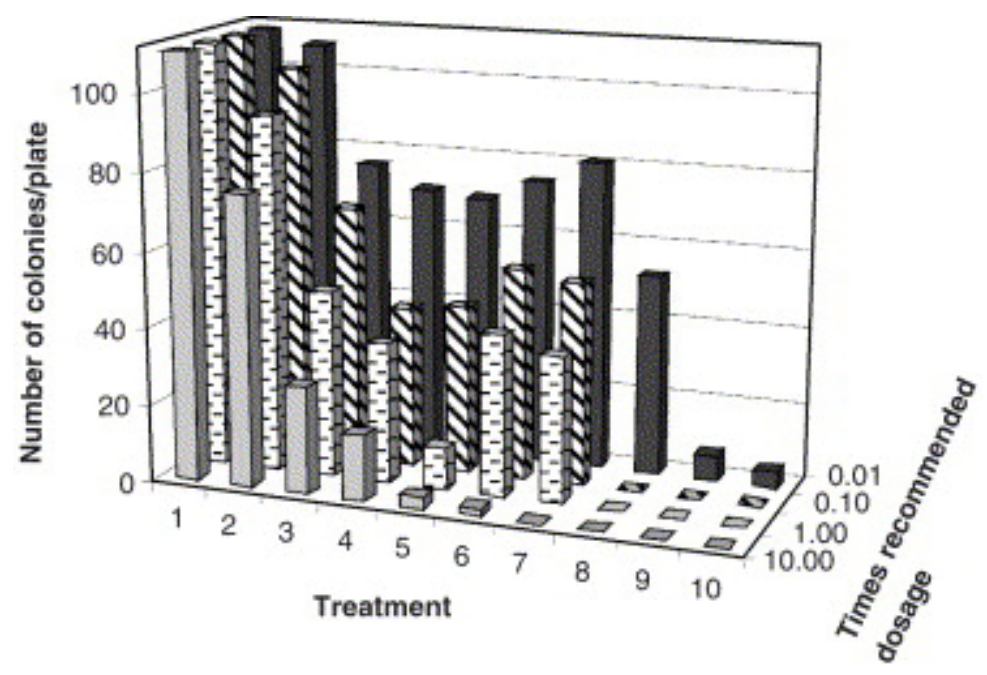

Fig. 3. Effect of surface sterilants and fungicides at different concentrations of the product on survival of Fusarium oxysporum f.sp. cubense, tested at a spore concentration of $10^{2}$ spore $\mathrm{ml}^{-1}$. Treatments were as follow: (1) control, (2) Chloride, (3) Omega, (4) 
Cupravit (copper oxychloride), (5) Farmcleanse, (6) Clean Green, (7) Desogerm, (8) Prazin Agri, (9) Jik, and (10) Sporekill. Mean value determined by the General Linear Model Procedure (GLM) $(\boldsymbol{P} \leqslant \mathbf{0 . 0 5}) . \mathrm{LSD}=2.795$.

\section{Discussion}

DMI fungicides, which include the imidazoles (prochloraz) and the triazoles (propiconazole and cyproconazole/propiconazole), are one of the most important groups of fungicides (Baldwin and Rathmell, 1988). They are also known as the "azole group". It is this group of fungicides that showed the greatest effectiveness in inhibiting Foc growth in vitro as well as suppression of the disease in the greenhouse. DMI fungicides are a chemically diverse group, and they act by inhibiting the demethylation step in the biosynthesis of sterol, which is needed in fungal cell walls. They most likely bind to cytochrome P-450 involved in sterol demethylations (Uesugi, 1998).

Prochloraz and cyproconazole/propiconazole proved to be the most effective against FoC of all fungicides evaluated in this study. Similar results have been reported on the use of prochloraz against other Fusarium spp. (Strauss and Labuschagne, 1993; Song et al., 2004). Strauss and Labuschagne (1993) found prochloraz to be the most effective fungicide against Fusarium solani (Mart.) Sacc. in vitro and in vivo. Applying the fungicide as a drench treatment to citrus seedlings 7 days after inoculation with $F$. solani effectively eradicated the fungus from feeder roots. Song et al. (2004) found prochloraz and carbendazim to be the most effective fungicides in inhibiting mycelial growth of $F$. oxysporum causing Fusarium wilt of tomato. They also observed in a hydroponic cultivation system that prochloraz had a preventative effect of $69.9 \%$ and a curative effect of $34.4 \%$.

Benomyl is a systemic fungicide that acts as a multiplication inhibitor during fungal mitosis (Uesugi, 1998). In the current study, benomyl inhibited the mycelial growth of both FOC isolates effectively at a concentration greater than $10 \mu \mathrm{g} \mathrm{ml} \mathrm{m}^{-1}$ (a.i.). In the greenhouse trials benomyl was most effective, especially as a soil drench treatment 1 week after planting and as a root dip treatment. Similarly, Allen et al. (2004) performed in vitro fungicide evaluations against Fusarium circinatum Nirenberg \& O'Donnell, $F$. oxysporum, Fusarium proliferatum (Matsush.) Nirenberg ex Gerlach \& Nirenberg and F. 
solani. They found that benomyl at all concentrations completely inhibited fungal growth of all four Fusarium species. However, prochloraz and cyproconazole/ propiconazole were not included in their study. Ram et al. (2004) reported that benomyl was the most effective treatment for the control of corm rot caused by F. oxysporum f.sp. gladioli, followed by carbendazim and captab. They also observed that dip treatments of $60 \mathrm{~min}$ were much more effective than 30 min treatments.

It is notable that phosetyl-Al showed slight inhibition of Foc mycelial growth in vitro, while no significant effect on disease severity was observed in the greenhouse. The fungicide is reported to act both directly on a pathogen (Fenn and Coffey, 1984) and indirectly by inducing host defense responses (Guest, 1984). Phosetyl-Al is known to be mainly effective for control of diseases caused by the Peronosporales (Cohen and Coffey, 1986). It was, therefore, not too surprising that phosetyl-Al was ineffective against Foc in vivo.

Chemical control can be combined with biological control products in an integrated disease management programme. Elmer and McGovern (2004) combined commercial biological products comprising beneficial microbes with fungicides and found that the combination provided a higher degree of suppression of Fusarium wilt of cyclamen. Similarly, Minuto et al. (1995) found an enhanced degree of control against Fusarium wilt of cyclamen after the combination of the benzimidazole fungicide carbendazim and antagonistic Fusarium spp. Fungicides have the potential to be part of an integrated disease management programme for Fusarium wilt of banana. However, fungicides could only be applied to banana plants by means of soil drenches or root dipping, since stem injections have proved to be ineffective in the past (Herbert and Marx, 1990). It is also important to determine what impact these fungicides will have on the natural soil microflora and suppressiveness of the soil, and what combination of biological control agents can be applied with these fungicides.

It was observed in the current study that more effective surface sterilants than the ones previously used against FOC contamination are available on the market. The quaternary ammonium compounds such as Sporekill and Prazin are generally considered as fastacting disinfectants and are active at low concentrations (Tanner, 1989). Sporekill showed efficacy against Foc conidia at an exposure time of only $30 \mathrm{~s}$. This makes 
Sporekill a highly effective compound for the sterilization of Foc contaminated equipment, vehicles and shoes in the field. Jik and Prazin, at low concentrations, also complete killed Foc conidia as reflected in a reduced number of colonies developing on PDA. These compounds, therefore, can also be used for sterilization purposes. These three compounds were more effective against Foc than copper oxychloride and farmcleanse, which have been used in water baths and for disinfection of machinery, field equipment and workers' shoes in South Africa and Australia, respectively. Prochloraz was also included in the sterilization experiment to determine its effectiveness on Foc conidia. Prochloraz, being a fungicide rather than a sterilant, was however, far less effective for this purpose.

In South Africa surface sterilants are already part of the integrated disease management programme of banana. However, copper oxycloride that was used in the past proved to be ineffective. Based on the findings of the current study, farmers in South Africa have been informed that copper oxychloride should be replaced with Sporekill or Prazin. Sporekill and Prazin are relatively inexpensive, environmentally friendly, non-toxic and noncorrosive sterilants. Since there are currently no effective control measures available for the control of Fusarium wilt of banana, prevention is of critical importance. Many farmers have not yet adopted any preventative strategies and they can, therefore, contribute to the spread of Fusarium wilt of banana.

\section{References}

Allen et al., 2004 T.W. Allen, S.A. Enebak and W.A. Carey, Evaluation of fungicides for control of species of Fusarium on longleaf pine seed, Crop Prot 23 (2004), pp. 979-982. Baldwin and Rathmell, 1988 B.C. Baldwin and W.G. Rathmell, Evolution of concepts for chemical control of plant disease, Annu. Rev. Phytopathol. 26 (1988), pp. 265-283.

Booth, 1977 C. Booth, Fusarium. Laboratory Guide to the Identification of the Major Species, Commonwealth Mycological Institute, Kew, Surrey, UK (1977).

Brandes, 1919 E.W. Brandes, Banana wilt, Phytopathology 9 (1919), pp. 339-389. Carlier et al., 2002 Carlier, J., De Waele, D., Escalant, J.V., 2002. Global evaluation of Musa germplasm for resistance to Fusarium wilt, Mycosphaerella leaf spot diseases and nematodes. INIBAP Technical Guidelines 6, Montpellier, France. 
Cohen and Coffey, 1986 Y. Cohen and M.D. Coffey, Systemic fungicides and the control of oomycetes, Annu. Rev. Phytopathol. 24 (1986), pp. 311-338.

Corden and Young, 1959 Corden, M.E., Young, R.A., 1959. The effects of fungicides on Fusarium oxysporum f.sp. cubense and other soil microorganisms. U.F.-Oregon State College Annual Reports.

Corden and Young, 1960 Corden, M.E., Young, R.A., 1960. The effects of fungicides on Fusarium oxysporum f.sp. cubense and the nature of wilt disease resistance. U.F.-Oregon State College Annual Reports.

Deacon, 1984 J.W. Deacon, Panama disease of banana in South Africa, Hortic. Sci. 1 (1984), pp. 29-31.

Elmer and McGovern, 2004 W.H. Elmer and R.J. McGovern, Efficacy of integrating biologicals with fungicides for the suppression of Fusarium wilt of cyclamen, Crop Prot. 23 (2004), pp. 909-914.

Fenn and Coffey, 1984 M.E. Fenn and M.D. Coffey, Studies of the in vitro and in vivo antifungal activity of phosetyl-Al and phosphorous acid, Phytopathology 74 (1984), pp. 606-611.

Groenewald et al., 2006 S. Groenewald, N. Van den Berg, W.F.O. Marasas and A. Viljoen, Biological, physiological and pathogenic variation in a genetically homogenous population of Fusarium oxysporum f.sp. cubense, Australas. Plant Pathol. 35 (2006), pp. 401-409.

Guest, 1984 D.I. Guest, Modification of defence responses in tobacco and capsicum following treatment with phosetyl-Al [Aluminium tris(O-ethyl phosphonate)], Physiol. Plant Pathol. 25 (1984), pp. 123-134.

Gullino et al., 2000 M.L. Gullino, P. Leroux and C.M. Smith, Uses and challenges with novel compounds for plant disease control, Crop Prot. 19 (2000), pp. 1-11.

Herbert and Marx, 1990 J.A. Herbert and D. Marx, Short-term control of Panama disease in South Africa, Phytophylactica 22 (1990), pp. 339-340.

Jeger et al., 1996 M.J. Jeger, J.M. Waller, A. Johanson and S.R. Gowen, Monitoring in banana pest management, Crop Prot 4 (1996), pp. 391-397. 
Lakshmanan et al., 1987 P. Lakshmanan, P. Selvaraj and S. Mohan, Efficiency of different methods for the control of Panama disease, Trop. Pest Manage. 33 (1987), pp. 373-376.

Meredith, 1943 C.H. Meredith, Mercury compounds applied to banana plants in the field, Phytopathology 33 (1943), pp. 835-836.

Minuto et al., 1995 A. Minuto, Q. Migheli and A. Garibaldi, Evaluation of antagonistic strains of Fusarium spp. in the biological and integrated control of Fusarium wilt of cyclamen, Crop Prot 14 (1995), pp. 221-226.

Moore et al., 1999 N.Y. Moore, K.G. Pegg, L.J. Smith, P.W. Langdon, S. Bentley and M.K. Smith, Fusarium wilt of banana in Australia. In: A.B. Molina, N.H.N. Masdek and K.W. Liew, Editors, Banana Fusarium Wilt Management: Towards Sustainable Cultivation. Proceedings of the International Workshop on Banana Fusarium Wilt Disease, Genting Highlands Resort, Malaysia (1999).

Moore et al., 1995 Moore, N.Y., Bentley, S., Pegg, K.G., Jones, D.R., 1995. Fusarium wilt of banana. Musa disease fact sheet no.5. INIBAP, Montpellier, France.

Ploetz, 1994 R.C. Ploetz, Panama disease: return of the first banana menace, Int. J. Pest Manage. 40 (1994), pp. 326-336.

Ploetz and Pegg, 1997 R.C. Ploetz and K.G. Pegg, Fusarium wilt of banana and Wallace's line: was the disease originally restricted to his Indo-Malayan region?, Australas. Plant Pathol. 26 (1997), pp. 239-249.

Ploetz and Pegg, 2000 R.C. Ploetz and K.G. Pegg, Fungal diseases of root, corm and pseudostem. In: D.R. Jones, Editor, Diseases of Banana, Abacá and Enset, CAB International, Wallingford, UK (2000), pp. 143-172.

Ploetz et al., 2003 R.C. Ploetz, J.E. Thomas and W.R. Slabaugh, Diseases of banana and plantain. In: R.C. Ploetz, Editor, Diseases of Tropical Fruit Crops, CAB International, Wallingford, UK (2003), pp. 109-112.

Ram et al., 2004 R. Ram, S. Manuja, D. Dhyani and Mukherjee, Evaluations of fortified fungicide solutions in managing corm rot disease of gladiolus caused by Fusarium oxysporum, Crop Prot 23 (2004), pp. 783-788.

Rishbeth and Naylor, 1957 J. Rishbeth and A.G. Naylor, Fusarium wilt of bananas in Jamaica. III. Attempted control, Ann. Bot. 21 (1957), pp. 599-609. 
Sokal and Rohlf, 1981 R.R. Sokal and F.J. Rohlf, Biometry: The Principles and Practice of Statistics in Biological Research, W.H. Freeman \& Company, San Francisco (1981). Song et al., 2004 W. Song, L. Zhou, C. Yang, X. Cao, L. Zhang and X. Liu, Tomato Fusarium wilt and its chemical control strategies in a hydroponic system, Crop Prot 23 (2004), pp. 243-247.

Stover, 1962 R.H. Stover, Fusarial Wilt (Panama disease) of Bananas and Other Musa Species, Commonwealth Mycological Institute, Kew, Surrey, UK (1962).

Strauss and Labuschagne, 1993 J. Strauss and N. Labuschagne, In vitro and in vivo effect of fungicides on Fusarium solani associated with citrus roots, Appl. Plant Sci. 7 (1993), pp. 56-59.

Tanner, 1989 R.S. Tanner, Comparative testing and evaluation of hard-surface disinfectants, J. Ind. Microbiol. 4 (1989), pp. 145-154.

Uesugi, 1998 Y. Uesugi, Fungicide Classes: Chemistry, Uses and Mode of Action. In: D. Hutson and J. Miyamoto, Editors, Fungicide Activity, Chemical and Biological Approaches to Plant Protection, Wiley, Chichester, England (1998), pp. 23-56. Viljoen, 2002 A. Viljoen, The status of Fusarium wilt (Panama disease) of banana in South Africa, S. Afr. J. Sci. 98 (2002), pp. 341-344.

Wardlaw, 1961 C.W. Wardlaw, Banana Diseases, Including Plantains and Abaca, Longmans, Green and Co. Ltd, London (1961).

Corresponding author. Tel.: +27 12420 3856; fax: +27 124203960 . 